Jürgen HABERMAS. - Theorie des kommunikativen Handelns, Suhrkamp, Francfort, 1981.

Articula aquí Habermas el contenido de las demás obras suyas bajo el hilo conductor de la «acción comunicativa». En el fondo, los dos tomos de la Teoría de la acción comunicativa constituyen una teoría de la sociedad moderna y de su proceso de racionalización.

La manera de desarrollar su trabajo no es nueva. En discusión con otros autores (Mead, Durkheim, M. Weber, Marx, Horkheimer, Adorno) que han abordado el tema de la sociedad actual, Habermas se apropia el material elaborado por ellos y quiere perfeccionarlo mediante su teoría de la acción comunicativa.

La duplicidad de trabajo e interacción, que proviene de obras anteriores, se convierte aquí en la pareja de conceptos mundo de vida, articulado mediante el lenguaje comunicativo, y siste$m a$, que comprende la dirección estatal y la economía.

Asume de los autores con los que entra en discusión la idea básica de que la moderna sociedad capitalista (y marxista) surge por una preeminencia de la acción medio-fin sobre las demás dimensiones de la vida humana. En tanto este mundo social constituye una unidad interrelacionada sobre la base de ciencia técnica, puede hablarse de la racionalización científica o técnica de la vida, o también de la constitución de un sistema racional que se conserva y transforma en simbiosis con el entorno.

Pero la pregunta de Habermas es si este tipo de racionalidad descansa en sí misma o, por el contrario, ha de enlazarse con una paralela y previa tacionalidad procedente de la esfera comunicativa (mundo de vida). Aprovechando los análisis de $\mathrm{M}$. Weber sobre las racionalizaciones a través de las religiones, hasta llegar a la reforma protestante (sobre todo, ética profesional del calvinismo), Habermas sostiene que la diferenciación y especialización del moderno metcado burgués no hubiera sido posible sin una eleva. ción previa del nivel de racionalidad en el mundo de vida. Cabe señalar, por ejemplo, los siguientes estadios: unidad indiferenciada de moral y acción técnica, moral ligada al contenido, universalización religiosa de la moral, universalización de una moral autónoma con independen- cia del contenido material y de la fundamentación religiosa.

Mientras el mundo de vida asentaba su unidad en un tronco metafísico o religioso, existía en cierto modo una unidad de la razón o una razón substancial. Pero Habermas plantea su problemática fundamental desde el contexto en que, por la diferenciación de los diversos ámbitos humanos, se van constituyendo las racionalidades particulares (arte autónomo, campos de la ciencia, economía, etc.), y, con ello, se escinde la unidad de la razón. Desde ese momento el mundo de vida (dejemos de lado en qué medida la texminología de Habermas está marcada por el influjo de Husserl, Heidegger...), queda vertebrado también por una manera peculiar de autonomía o racionalidad, consistente en las normas de conducta que sostienen la intersubjetividad y emanan de ella. Esta intersubjetividad normativa es autónoma o racional en tanto se instaura discursivamente, o sea, mediante razones que amparan la respectiva pretensión de validez.

Tenemos así dos esferas racionalizadas en forma paralela $\mathrm{e}$ interdependiente: el mundo de vida, y el sistema del mercado bajo la dirección estatal. Aunque Habermas no pretende restablecer la unidad de una tazón substancial (pues la razón no tiene ahora más unidad que la formal, la de argumentar por razones en los diversos sectores materiales), aspira, sin embargo, a una coherencia de las razones (sin que quede explicitado el porqué de esta aspiración a la coberencia). Lo cual signica, sobre todo, que resulta insostenible la independencia total del sistema frente al mundo de vida. Por ejemplo, el mercado, mediante la figura del contrato, recutre constantemente al mundo de vida, ya que el contrato no es posible sin el consenso intersubjetivo, que remite a la dimensión de la moralidad. O bien, por citar otro ejemplo, los valores que llegan a comercializarse surgen previamente en la intersubjetividad comunicativa (mundo de vida).

Esto supuesto, ¿cómo enfoca Habermas el mundo moderno, concretamente el hecho de que el sistema del metcado comercializa el mundo de la vida en su totalidad y se alza como único paradigma de moralidad consistente? En principio, Habermas no enjuicia negativamente la diferenciación del mercado y de los diversos sectores 
autonómicos, pues esto se hace necesario cuando la vida alcanza un determinado nivel de complejidad. Lo cual significa que para Habermas la alienación o cosificación no se cifra precisamente en la regulación de las relaciones laborales pot el medio del dineto. El desajuste to lo patológico) de la situación actual es caracterizado ahora como colonización del mundo de vida (de la esfera comunicativa, de las relaciones intersubjetivas).

La colonización consiste en que la razón instrumental (utilizando la expresión acuñada por Horkheimer y Adorno) no se ciñe a su esfera de competencia, sino que somete a su medio categorial parcelas que pertenecen a la dimensión típicamente comunicativa, la cual, con igual derecho que la esfera del sistema, goza de su propia autonomía y racionalidad.

Si la patología está en la colonización, es in. dudable que la terapéutica habrá de consistir en la descolonización. La patología se cifra en la reacción del mundo de vida, que se siente agredido en sus raíces vitales, que se siente amenazado en su equilibrio vital. Por eso Habermas busca el potencial revolucionario en los movimientos de protesta contra la hegemonía y los desmanes del sistema de mercado. $Y$ de cara a la praxis futura el mensaje de Habermas no puede interpretarse sino como una recuperación del equilibrio entre el mercado y la vida, de tal manexa que aquél mantenga su propia autonomía, pero ésta, a su vez, se coordine con la autonomía de la intersubjetividad comunicativa e incluso acepte la primacía de la misma.

Por tanto, según decíamos, la alienación no va ligada a la cosificación en cuanto tal, o sea, al hecho de que el sistema de autoconservación (o producción) del hombre se articule a través del medio objetivo o cósico del dinero, no va ligada al trabajo abstracto, es decir, a la desvinculación entre el trabajo concreto del individuo y el fruto concreto de su trabajo, sino al hecho de que se instrumentalice o cosifique lo que, de por sí, no es instrumentalizable o cosificable. $Y$ esto es lo que, por implicar un alter ego, no puede someterse al cálculo de los medios para mis fines, sino que ha de sincronizarse en un consenso cabal, en la validez intersubjetiva de lo que es justo precisamente porque es común y compartido, y porque, siendo común y compar. tido, constituye aquella comunidad en la que se identifican el ego y el alter ego. En tanto el sistema impide la expansión de tales ámbitos comunicativos, reprime la vida y la subjetividad libre.

Es importante preguntar desde qué foro de certeza, conocimiento o saber enjuicia y critica Habermas. El mismo responde que no pretende erguirse, por ejemplo, desde un privilegiado saber filosófico, con evidencia primera, o apriorística, o trascendental, sino que se limita a analizar estructuras de racionalidad subyacentes de manera inconsciente en un mundo humano y social que nos viene dado previamente. Estos elementos previamente dados que Habermas saca a la luz, se comportan como hipótesis de tra" bajo científico cuya validez ha de medirse por su capacidad de esclarecer consistentemente los hechos que se producen en la transición a la moderna sociedad capitalista.

La teoría habermasiana de la acción comunicativa implica el propósito decidido de terminar con la filosofía de la conciencia, o sea, con el intento de interpretar la realidad desde un yo so. litario que conoce. La alternativa frente a este yo solipsista sólo puede ser el interego, la intersubjetividad comunicativa. Y esto equivale a la afirmación de que el yo sólo logra su identidad a través del otro. Desde aquí se explica que $\mathrm{Ha}$ bermas busque las categorías de la realidad, no a través de un inventario de la conciencia subjetiva, ni por el análisis de la relación entre el sujeto cognoscente y el objeto conocido, sino a través de las pretensiones de validez que actúan en el lenguaje ordinario y, concretamente, en la estructura de un acto lingüístico normal. En efecto, si lo real es to intersubjetivo y compartido, es lógico que las articulaciones de la realidad se busquen en aquellas modalidades del lenguaje por las que recabamos la aquiescencia de otro (verdad, legitimidad, aceptación de nuestras manifestaciones).

En cuanto al desarrollo de la obra misma, nuevamente tengo que insistir en la profusión de Habermas y en la dificultad de su lectura. Se requiere tenacidad y paciencia para leer las 1167 páginas que suman sus dos tomos. Éstos constan de un conjunto de discusiones con los autores básicos que han abordado el problema de la racionalización de la sociedad moderna. La clave de la discusión con cada uno de esos autores está siempre en que ninguno de ellos ha 
tenido debidamente en cuenta la autonomía peculiar de la racionalidad del sistema y de la racionalidad comunicativa. Creo que casi todos los lectores se preguntarán por qué Habermas no va más directamente al grano, por qué no toma como hilo conductor el desarrollo de su propia teoría de la acción comunicativa, para lievarla adelante progresivamente a través de su obra. El que quiera recomponer los pasos de esta teo. tía, habrá de tomar un trozo de aquí, otro de allá, y rehacerlos en una unidad.

Comparada esta obra de Habermas con otros escritos del mismo autor, podemos decir, por una parte, que no contiene elementos sensacionalmente nuevos, $y$, por otra, que el autor quie. re mostrarnos ahora la teoría axial de su propio pensamiento. Esta teoría, que es la de la acción comunicativa, asume la distinción anterior entre trabajo e interacción, y, en estrecha síntesis con los estudios lingüusticos de Habermas, se nos presenta ahora como un estudio de la relación entre racionalidad económica y lenguaje comunicativo. Lenguaje y dinero aparecen así como los dos grandes medios de la sociedad actual.

Lo que no queda claro es cómo Habermas, si quiere romper con la filosofía solipsista de la conciencia y pasar al paradigma de la racionalidad comunicativa, puede, sin embargo, aceptar la racionalidad del sistema (y de la ciencia im. plicada en él), que funciona por la acción estratégica y la acción medjo-fin, solipsistas en cuan. to tales. Si acepta esta racionalidad, ¿puede deshacerse de la problemática del ego que conoce también en solitario? Sería más cómodo para Habermas reducirlo todo al simbolismo de la in. tersubjetividad linguiística, e implícitamente lo hace. Pero tiene la forzada honradez de dejar entrever que la empresa no acaba de cuajar. En todo caso, del fondo de su obra emerge la gran pregunta de la sociedad actual: ¿Quién funda la comunidad cuando el hombre ha sido desamparado por los dioses y las metatísicas? Habermas no se siente legitimado para remontarse a ninguna metafísica y, por tanto, no tiene más horizonte último que la intersubjetividad activa, transmitida a través de la historia. Los metafísicos, sin embargo, seguirán preguntando si la intersubjetividad no brota de la subjetividad lo. grada y si no es ésta la que naufraga en la modernidad avanzada, bajo el peso de una intersubjetividad desubjetivada. Habermas denuncia pre. cisamente este hecho, pero con un deje de inseguridad sobre la instancia contrafáctica desde la cual pueda formularse la denuncia.

No obstante, aunque sea legítima la pregunta anterior, la insistencia excesiva en ella desvirtuaría la intención fundamental de Habermas, que es encontrar un marco categorial para explicar el fenómeno de la sociedad contemporánea. $\mathrm{Y}$, bajo este aspecto, hemos de reconocer en la obra comentada una producción cimera en el esfuetzo por comprender nuestra sociedad.

\section{Raúl Gabás}

Antoni REMESAR, Carles RIBA, José Luis RODRIGUEZ ILLERA, Tres ensayos sobre comunicación, Ediciones Mascarón, Barcelona, 1982.

Difícilmente podríamos decir que Tres ensayos sobre comunicación, obra recientemente publicada, de Antoni Remesar, Carles Riba y José Luis Rodríguez Illera, llena algún hueco en la bibliografía castellana sobre comunicación; más bien tenemos que decir que, afortunadamente, ya hay uno más de los poquísimos que se editan sobre el tema, y posiblemente no cometeremos ningún error apuntando que éste es el primero de los editados en castellano que intenta la exótica confluencia de los enfoques de la Etología, la comunicación no verbal y lo que ha dado en llamarse «Psicología de la Comunicación».

Es ésta una obrita engañosa que reúne tres textos de carácter y enfoque desigual, aunque fruto de una puesta en común como dicen sus autores, de lectura en algunos casos enrevesada, pero que no dejará de interesar a aquellos que pasan su tiempo llevándose los prismáticos a los ojos, la mayor parte de las veces por pura afi. ción -casi por cotilleo interespecífico-, a los que busquen una obra realmente informativa so. bre las corrientes de investigación en comunicación no verbal que sea algo más que un salpicón poco sabroso y a aquellos, en fin, que se sientan atraídos por las, en otras partes viejas y aquí nuevas, teotías sobre la comunicación humana. 